\title{
Causal item of Brief Illness Perception Questionnaire (BIPQ) scale: The main categories
}

\author{
Justė Lukoševičiūtè, ${ }^{1}$ Kastytis Šmigelskas ${ }^{1,2}$ \\ ${ }^{1}$ Health Research Institute and ${ }^{2}$ Department of Health Psychology, Faculty of Public Health, \\ Medical Academy, Lithuanian University of Health Sciences, Kaunas, Lithuania
}

\begin{abstract}
The causal item of illness perception from Brief Illness Perception Questionnaire (BIPQ) has no clearly defined response categories. It restricts the comparison of findings across studies on illness perception. Therefore, this study analyzed the causal item
\end{abstract}

\author{
Correspondence: Justė Lukoševičiūtè. Health Research Institute, \\ Faculty of Public Health, Lithuanian University of Health Sciences. \\ Tilžès g. 18, Kaunas LT-47181, Lithuania. \\ Tel. +37037242908 . \\ E-mail: juste.lukoseviciute@1smuni.lt
}

Key words: Acute coronary syndrome, BIPQ, illness causes, illness perception, health outcomes.

Acknowledgments: The authors would like to thank the patients for contribution to this study and bringing new knowledge about illness perception.

Contributions: the authors contributed equally.

Conflict of interests: the authors declare no potential conflict of interests.

Conference presentation: Lukoševičiūtė, J., Šmigelskas, K. (2018). "Ligos suvokimas kardiologinès reabilitacijos pradžioje ir su juo susiję veiksniai“. [Illness perception at early cardiac rehabilitation and related factors]. Lithuanian congress of psychologists, Klaipeda, May 17-19, 2018.

Funding: None.

Availability of data and materials: Not applicable.

Ethics approval and consent to participate: BEC-SP(M)-105

Informed consent: Informed consent has been obtained.

Conflict of interests: the authors report no conflict of interests.

Received for publication: 10 August 2019.

Accepted for publication: 7 April 2020.

This work is licensed under a Creative Commons AttributionNonCommercial 4.0 International License (CC BY-NC 4.0).

(C) Copyright: the Author(s), 2020

Licensee PAGEPress, Italy

Health Psychology Research 2020; 8:8485

doi:10.4081/hpr.2020.8485 responses and proposed a categorization structure. The cohort study measurements were conducted at early cardiac rehabilitation and six months later. Illness perception was assessed using BIPQ scale with qualitative responses of causal item being independently coded by two researchers who assigned the responses to categories using template analysis approach. The study identified seven main causal categories of illness perception: lifestyle, psychological causes, natural causes, working conditions, body changes, environmental factors, and other causes. The perception that acute coronary syndrome is mainly due to lifestyle factors associates with better health-related outcomes compared to other causal perceptions. The proposed categorization of BIPQ causal item could be tested in the future research among different samples accounting only the main cause.

\section{Introduction}

Perception of a person's illness depends not only on a medical profile of the disease but also on patient's attitude towards his disease and its possible threat to health or life. Given this, the illness perception differs from patient to patient, even with the same disease or under similar conditions (Lambregts, 2017).

Leventhal and his colleagues (1980) were the first ones who started research on illness perception and had based it on the Common-Sense Model of illness representation. This model comprises five components of illness perception: identity, consequences, time line, cause, and cure (Lau \& Hartman, 1983). According to Leventhal et al. (1980), the illness perception has significant implications for how people react to disease, how they behave (treatment adherence, reduction of risk behaviors, doctorpatient relationship, etc.) as well as how they manage illness threat and distress. Moreover, recent studies confirmed that illness perception relates not only to adaptation to disease but disease outcomes as well (Petrie \& Weinman, 2006; Broadbent et al., 2015; Marke \& Bennett, 2017).

The first decade of illness perception research was based on qualitative studies (Leventhal \& Nerentz, 1985). Therefore, the increasing need for quantitative measure resulted in the first internationally known scale - the Illness Perception Questionnaire (IPQ), developed by Weinman et al. (1996) and based on cognitive aspects of illness perception. Quite soon Moss-Morris et al. (2002) introduced a Revised Illness Perception Questionnaire (IPQ-R) with a more detailed assessment of illness perception, additionally covering the emotional component. However, the latter scale was quite extensive ( 84 items) and could be burdensome in severe conditions or among the elderly. Therefore, in 2006 Broadbent et al. constructed a very short scale - Brief Illness Perception Questionnaire (BIPQ) with nine items only. This scale is the most used tool in recent research on illness perception. 
The nine items of BIPQ cover nine dimensions of illness perception (Broadbent et al., 2006). The first eight items are quantitative, and the ninth is qualitative: it is an open-ended question where the participant may indicate the three most important causes of his/her disease - and rank them by importance. The authors of BIPQ in their original paper mentioned that the analysis of causal item is likely to depend on the aims of the study' and responses are likely to be categorized (Broadbent et al., 2006). However, this has been not a common practice: later meta-analysis concluded that researchers should analyze the causal item more since previously most studies have omitted this. Typically, the studies that included causal item have categorized and described the most frequent responses, among which the psychological stress, genetics, and illness behaviors were most common (Broadbent et al., 2015). Nevertheless, the comparison of findings in studies that use different categorization is complicated due to overlapping or different categories and their contents.

The causal dimension of illness perception reflects the patients' individual opinion about what led to the onset of his or her disease (Lau \& Hartman, 1983) which is not necessarily medically correct (Leventhal et al., 1997). The perception of illness causes is often based on personal experience, discussions, and opinions with the people who are significant to the patient. It should also be noted that health professionals and media play an important role in shaping the perception of a certain disease causes, such as stress, environmental pollution or other factors (Leventhal et al., 1997).

Overall, the research on the causal dimension of illness perception is scarce. We suggest that the lack of analysis of causal item is not only due to the time-consuming nature of qualitative response analysis but also due to the absence of predefined categories for such responses. This absence of categories may explain the fact that there are only several studies reporting the causal item in clearly defined categories, such as by Weinman et al. (1996) or Duwe et al. (2014). The frame of response categories could enable the researchers to put the qualitative information of the causal item to quantitative responses that further could be analyzed and compared at a large scale. Therefore, our aim of this paper was to analyze the causal item responses empirically and propose the categorization structure for the causal item of illness perception.

\section{Materials and Methods}

\section{Procedure and participants}

The cohort study was conducted with assessments at the beginning of cardiac rehabilitation (baseline) and six months later. The baseline measurements took place in April-July 2017 at Kulautuva Rehabilitation Hospital of Lithuanian University of Health Sciences Kauno Klinikos, and follow-up was performed six months later (October 2017 to January 2018). The Ethics Committee for Biomedical Research, Lithuanian University of Health Sciences approved the study and its consent procedures (No. BEC-SP(M)-105). Written informed consent was obtained from each participant after a full explanation of the study aim and procedures. The study included patients with acute coronary syndrome who met following eligibility criteria: i) Patients aged 18 years and older; ii) Patients with acute coronary syndrome without surgical intervention; iii) Rehabilitation period not longer than three days; iv) Ability to communicate in Lithuanian.

In total, 214 patients met these criteria; 10 of them refused to participate in the study, 5 were urgently transferred to another hos- pital, and 4 had a cognitive disorder. Overall, 195 subjects participated at baseline assessment (response rate $91 \%$ of patients meeting the criteria), 175 of them were reached after six months followup $(90 \%$ of baseline sample). The patients were aged 27 to 89 years, two thirds $(67 \%)$ being men. Based on the clinical profile, unstable angina pectoris and myocardial infarction were almost similarly distributed ( $48 \%$ and $52 \%$, respectively), almost half $(46 \%)$ of respondents had recurrent acute coronary syndrome, while the majority of patients $(57 \%)$ were classified as Functional Capacity II by New York Heart Association (NYHA) classification. Detailed baseline characteristics of the study sample are presented in Table 1.

\section{Measures}

The baseline measurements were conducted using self-reported questionnaires. If patients were unable or not keen to fill in the questionnaire independently, the researcher asked them verbally item by item and filled in the questionnaire herself. The clinical data were collected from patients' medical records and their physicians, while sociodemographic indicators were self-reported.

Table 1. Sociodemographic and clinical characteristics of study sample.

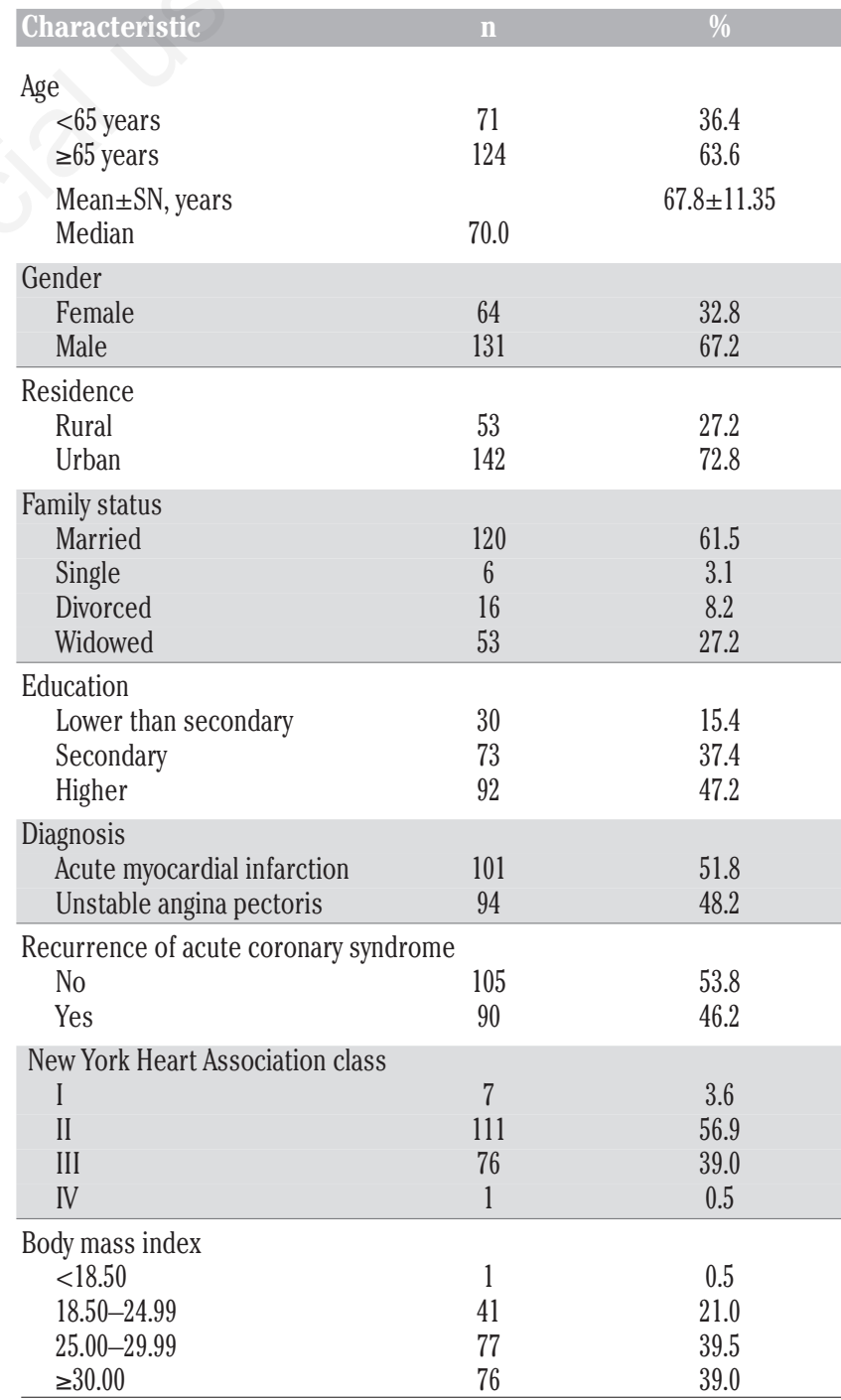


Illness perception was assessed using the Brief Illness Perception Questionnaire (Broadbent et al., 2006), consisting of 9 items that represent nine dimensions of the construct. The first eight items (Consequences, Timeline, Personal control, Treatment control, Identity, Concern, Understanding, Emotional response) were assessed using a Likert scale from 0 to 10 , comprising the total score from 0 to 80 . The last item (Causes) was open-ended, asking the patient to indicate and rank the three most important causes of his/her disease.

The follow-up assessment was conducted by telephone survey six months after cardiac rehabilitation. The respondents were asked about their current health condition (related to cardiac disease deterioration) and hospitalization within the last six months.

\section{Formulation of causal categories}

For the definition of causal categories from an open-ended item the template analysis was used. The template analysis is a type of thematic analysis that is flexible regarding the style and format of the template that is used. This thematic approach does not suggest a sequence of coding levels beforehand - rather, it encourages the analyst to develop themes more extensively where the richest data are found. The data in template analysis studies are not only interview transcripts but also other kinds of textual data, including open-ended question responses on a written questionnaire (Brooks et al., 2015), that were specifically used in this study.

In this study, we tried to define the generic (not disease-specific) categories of causes. The primary set of possible causal categories was based on previous research (Weinman et al., 1996; Moss-Morris et al., 2002; Duwe et al., 2014; Broadbent et al., $2015)$ with an opportunity to add emerging new categories. The analysis of qualitative responses of causal item started with two researchers' (authors of this paper) independent coding of responses into the preliminary defined set of response categories that was later revised and amended. The final set consisted of seven categories:

- Lifestyle - the action/inaction that is mainly under the personal control of a patient and that leads to better or worse health.

- Psychological causes - psychological responses to the social environment (family, work, etc.) and events as well as personality traits. A person usually feels being unable to control these factors.

- Natural causes - inherited or unchangeable characteristics of the body, usually present from the birth or naturally occurring with aging. A person has no control over these factors.

- Working conditions - circumstances and factors at workplace, except psychological causes (such as stress at work). These factors are avoidable by changing the workplace.

- Body changes - characteristics of the body that change over time, mainly due to physiological but also to anatomical responses to environment, lifestyle or illnesses.

- Environmental factors - the surrounding physical environment that may affect a person's health. These factors are hard to avoid because they are widely prevalent and can hardly be changed personally.

- Other causes - discrete or non-specific responses, also the causes that cannot be classified to any of abovementioned categories.

In cases when the respondents did not indicate any cause of illness, their responses were classified as missing and were not analyzed. The validity of categorization as the inter-rater agreement was assessed through Cohen's kappa coefficient $(\kappa)$ which was 0.92 and could be considered as very high (Fleiss, 1981; Landis \& Koch, 1997).

\section{Statistical analysis}

The data were entered and analyzed using MS Excel and IBM SPSS 20.0 software. Univariate analysis included means and standard deviations $( \pm \mathrm{SD})$ for continuous data and percentages for categorical ones. Comparisons of means were conducted using Student's t-test for independent samples with regard to Levene's test for equality of variances. The chi-squared $\left(\chi^{2}\right)$ test and Fisher's exact test were used to compare categorical variables between the groups. The significance level was set at $\mathrm{p}<0.05$.

The importance of causal categories was analyzed using two analytical approaches. The first approach included only the first cause mentioned by respondents, i.e. the main perceived cause of acute coronary syndrome (as discrete variable). It was analyzed as percentage distributions. The second approach included all three mentioned causes with taking into consideration the ranking order and calculating the coefficient of importance for every category: the cause was rated with 3 points if mentioned as the first, with 2 points - as the second, with 1 point - as the third cause of disease, and with 0 points - if not mentioned. Thus, every category of causes could be rated from 0 to 3 points - the bigger the score, the higher perceived importance. If some of the several mentioned causes were from the same category, they were counted as one. The comparison of two approaches was conducted calculating the Spearman correlation coefficient $(\rho)$ which was also used to assess the associations among the rankings of different causal categories.

\section{Results}

\section{Illness perception among acute coronary syndrome patients}

Analysis of illness perception by its dimensions revealed that the most threatening aspect of acute coronary syndrome was illness timeline, i.e. perception that the disease will continue quite long ( $7.7 \mathrm{pts}$ out of 10 , on average). Another two threatening aspects were feeling concerned about the disease (6.3 pts) and about its consequences - the representation that the acute coronary syndrome will affect the life seriously (6.2 pts). Other dimensions of illness perception had medium or lower levels of threat (Table 2). Comparison of illness perception by the sociodemographic and clinical profile of patients demonstrated that more threatening overall illness perception was more characteristic $(p<0.05)$ for older patients ( $\geq 65$ years), women, and patients with more severe cardiac condition (NYHA class III-IV). These illness perception differences were observed mostly due to the different representation of illness consequences, understanding of the disease, and emotional response to it. The type of diagnosis was almost not associated with illness perception, except that the perceptions of timeline and understanding were perceived as more threatening among patients with angina pectoris (Table 2).

\section{Perception of illness causes}

In total, $93.8 \%$ of patients indicated at least one factor that they perceived as a cause of acute coronary syndrome. The importance of causal categories was assessed by analyzing the main cause and the coefficient of importance (Table 3 ). The comparison of two approaches showed very high correlation $(\rho=0.99 ; p<0.001)$ since both approaches revealed an almost identical sequence of categories by importance - the first being lifestyle, then psychological causes, natural causes, working conditions, body changes, other causes, and environmental factors. 
In order to assess whether rankings of causal categories are associated, the correlations were calculated. The results showed that majority of correlations were very low $(\rho<0.2)$ except three of them $(\mathrm{P}<0.05)$ : lifestyle causes correlated with body changes $(\rho=0.25)$ and with psychological causes $(\rho=0.24)$, while natural causes correlated with working conditions $(\rho=0.21)$.

Further, the seven causal categories will be presented in detail. Of note, the presentation of particular causes does not take into account the importance of them as ranked by patients. The overview of empirical responses is presented in Figure 1.

Lifestyle was the category that was mentioned by patients most frequently - both as the main cause and as the second or the third. Specifically, the patients reported the main conventional risk factors for cardiovascular diseases that are related to unhealthy lifestyle. These were diet, tobacco smoking, alcohol consumption, and low physical activity. While the relevance of diet for illness onset was perceived quite typically, with emphasis on too high salt, sugar or fat, the physical activity in one of the cases was reported to be 'too intensive' (mentioned by a sportsman). Besides, some respondents wrote quite abstract responses, such as 'improper lifestyle', 'harmful habits', 'daily regime' or 'poor treatment adherence'.
Psychological causes was the second most frequently reported category. Here the patients mentioned not only personal characteristics such as nervousness, sensitivity, type A personality, but also the factors that are mainly attributed to the external environment, especially stress and tension. This category included both familyand work-related psychological causes. In addition, some participants also reported the psychological factors associated with specific situations, e.g. 'quarrels with relatives', or 'bereavement of spouse'. Several patients emphasized the emotional aspect of causes by mentioning 'emotional tension', 'emotional sensitivity' or just 'emotional factor'.

Natural causes were defined as causes of illness that occur independently of a person. The huge majority of responses in this category pointed to heredity - patients noted here the importance of heredity from family members or more abstractly reported 'genetics' or 'genes' being the cause of their illness. Several patients perceived that acute coronary syndrome occurred due to old age.

Working conditions from patients' perspective contributed to their disease less than the abovementioned causes. The responses mainly emphasized physical work, sometimes also mentioning hard work, intensive work, or work regime (such as 'shift work' or

Table 2. Illness perception and its dimensions in study sample.

\begin{tabular}{|c|c|c|c|c|c|c|c|c|c|}
\hline Characteristic & Total score & Consequences & $\begin{array}{l}\text { Ilness perc } \\
\text { Timeline }\end{array}$ & $\begin{array}{l}\text { ption and } \\
\text { Personal } \\
\text { control* }\end{array}$ & $\begin{array}{l}\text { ts dimensio- } \\
\text { Treatment } \\
\text { control* }\end{array}$ & $\begin{array}{l}\text { s, mean } \pm \\
\text { Identity }\end{array}$ & $\begin{array}{l}\text { D* } \\
\text { Concern }\end{array}$ & Understanding* & $\begin{array}{l}\text { Emotional } \\
\text { response }\end{array}$ \\
\hline $\begin{array}{l}\text { Age } \\
<65 \text { years } \\
\geq 65 \text { years } \\
P\end{array}$ & $\begin{array}{c}36.8 \pm 11.59 \\
42.5 \pm 10.7 \\
0.001\end{array}$ & $\begin{array}{c}5.5 \pm 2.84 \\
6.7 \pm 2.75 \\
0.004\end{array}$ & $\begin{array}{c}7.5 \pm 3.26 \\
7.9 \pm 2.98 \\
0.385\end{array}$ & $\begin{array}{c}5.5 \pm 2.50 \\
4.9 \pm 2.75 \\
0.112\end{array}$ & $\begin{array}{c}8.2 \pm 1.61 \\
7.6 \pm 2.58 \\
0.061\end{array}$ & $\begin{array}{c}3.9 \pm 2.65 \\
4.1 \pm 3.29 \\
0.608\end{array}$ & $\begin{array}{c}6.3 \pm 3.28 \\
6.3 \pm 3.54 \\
0.968\end{array}$ & $\begin{array}{c}6.9 \pm 2.94 \\
5.5 \pm 3.43 \\
0.003\end{array}$ & $\begin{array}{c}4.4 \pm 3.15 \\
5.6 \pm 3.46 \\
0.014\end{array}$ \\
\hline $\begin{array}{l}\text { Gender } \\
\text { Female } \\
\text { Male } \\
\text { P }\end{array}$ & $\begin{array}{c}43.7 \pm 10.89 \\
38.9 \pm 11.25 \\
0.005\end{array}$ & $\begin{array}{c}6.9 \pm 2.77 \\
5.9 \pm 2.83 \\
0.018\end{array}$ & $\begin{array}{c}8.1 \pm 2.98 \\
7.5 \pm 3.13 \\
0.198\end{array}$ & $\begin{array}{c}5.0 \pm 2.62 \\
5.2 \pm 2.70 \\
0.512\end{array}$ & $\begin{array}{c}7.5 \pm 2.77 \\
8.1 \pm 1.99 \\
0.129\end{array}$ & $\begin{array}{c}4.2 \pm 3.24 \\
3.9 \pm 2.99 \\
0.586\end{array}$ & $\begin{array}{c}\mathrm{a} \\
6.3 \pm 3.51 \\
6.3 \pm 3.41 \\
0.976\end{array}$ & $\begin{array}{c}5.4 \pm 3.49 \\
6.3 \pm 3.21 \\
0.084\end{array}$ & $\begin{array}{c}6.0 \pm 3.58 \\
4.8 \pm 3.23 \\
0.016\end{array}$ \\
\hline $\begin{array}{l}\text { Diagnosis } \\
\text { AMI } \\
\text { Angina pectoris } \\
\text { P }\end{array}$ & $\begin{array}{c}40.9 \pm 11.6 \\
40.0 \pm 11.10 \\
0.559\end{array}$ & $\begin{array}{c}6.4 \pm 2.98 \\
6.1 \pm 2.69 \\
0.476\end{array}$ & $\begin{array}{c}7.3 \pm 3.24 \\
8.2 \pm 2.85 \\
0.035\end{array}$ & $\begin{array}{c}5.2 \pm 2.66 \\
5.1 \pm 2.70 \\
0.768\end{array}$ & $\begin{array}{c}7.8 \pm 2.28 \\
7.9 \pm 2.30 \\
0.804\end{array}$ & $\begin{array}{c}4.1 \pm 3.11 \\
3.9 \pm 3.04 \\
0.745\end{array}$ & $\begin{array}{c}6.7 \pm 3.40 \\
6.0 \pm 3.46 \\
0.165\end{array}$ & $\begin{array}{c}5.6 \pm 3.49 \\
6.5 \pm 3.07 \\
0.044\end{array}$ & $\begin{array}{c}5.1 \pm 3.26 \\
5.3 \pm 3.55 \\
0.732\end{array}$ \\
\hline $\begin{array}{l}\text { NYHA class } \\
\text { I-II } \\
\text { III-IV } \\
\text { P }\end{array}$ & $\begin{array}{c}39.1 \pm 11.41 \\
42.6 \pm 10.95 \\
0.032\end{array}$ & $\begin{array}{c}5.9 \pm 2.89 \\
6.7 \pm 2.72 \\
0.057\end{array}$ & $\begin{array}{c}7.6 \pm 3.11 \\
7.9 \pm 3.05 \\
0.462\end{array}$ & $\begin{array}{c}5.3 \pm 2.50 \\
4.8 \pm 2.91 \\
0.167\end{array}$ & $\begin{array}{c}8.1 \pm 1.89 \\
7.5 \pm 2.77 \\
0.163\end{array}$ & $\begin{array}{c}4.1 \pm 2.92 \\
3.8 \pm 3.30 \\
0.419\end{array}$ & $\begin{array}{c}6.5 \pm 3.31 \\
6.0 \pm 3.62 \\
0.290\end{array}$ & $\begin{array}{c}6.7 \pm 3.08 \\
5.0 \pm 3.45 \\
0.001\end{array}$ & $\begin{array}{c}4.9 \pm 3.36 \\
5.6 \pm 3.42 \\
0.193\end{array}$ \\
\hline Total sample & $40.5 \pm 11.34$ & $6.2 \pm 2.84$ & $7.7 \pm 3.08$ & $5.1 \pm 2.67$ & $7.9 \pm 2.28$ & $4.0 \pm 3.07$ & $6.3 \pm 3.44$ & $6.0 \pm 3.32$ & $5.2 \pm 3.39$ \\
\hline
\end{tabular}

Note: AMI - acute myocardial infarction, NYHA - New York Heart Association. Higher scores indicate more threatening illness perception, ${ }^{*}$ reversed

Table 3. Perception of illness causes: categories and their importance.

\begin{tabular}{|c|c|c|c|c|}
\hline Category & $1^{\text {st }}$ cause & $\begin{array}{l}\text { xuse rankin } \\
2^{\text {nd }} \text { cause }\end{array}$ & $3^{\text {rd }}$ cause & Coefficient** \\
\hline Lifestyle & 30.3 & 25.6 & 5.1 & $1.5 \pm 1.28$ \\
\hline Psychological causes & 25.1 & 19.5 & 5.6 & $1.2 \pm 1.29$ \\
\hline Natural causes & 15.9 & 14.4 & 5.1 & $0.8 \pm 1.18$ \\
\hline Working conditions & 10.3 & 5.6 & 1.5 & $0.4 \pm 0.99$ \\
\hline Body changes & 9.7 & 5.1 & 1.0 & $0.4 \pm 0.97$ \\
\hline Environmental factors & 0.0 & 0.5 & 0.5 & $0.0 \pm 0.16$ \\
\hline Other causes & 2.6 & 1.0 & 0.5 & $0.1 \pm 0.52$ \\
\hline
\end{tabular}

*Percentage of responders who reported the category; **from 0 ('not important cause') to 3 ('the most important cause'), mean \pm SD. 
'night work'). Several patients paid attention to the harmful environment at work such as the presence of toxic chemical substances or high noise.

The category of body changes implies any anatomical or physiological processes that negatively affect the body. Here the patients reported different diseases and comorbidities, most typically hypertension, diabetes, hypercholesterolemia, overweight/obesity. However, the participants also reported the conditions that are not usually related to cardiovascular outcomes - from pneumonia or influenza to radiculopathy or head surgery. Some patients perceived the body changes as abstract symptoms (e.g. 'chest pain' or 'heart palpitations') while there was also one patient with very straightforward perception that 'blood vessels are obstructing'.

Environmental factors in our study were mentioned by two patients. One response was very abstract ('environment'), the other - specific ('radiation'). It can also be noted that none of the patients perceived these factors as the main cause of their illness.

The category of other causes included the responses that did not fall into any of the categories described above. For example, the patients mentioned economic conditions suggesting the lack of finances, radiation, the 'inappropriate treatment' or 'the whole life'.

The analysis of causal categories by sociodemographic (age, gender, education, residence, family status) and clinical indicators at baseline (diagnosis, recurrence, comorbidities, NYHA class, body mass index) revealed no specific associations $(\mathrm{p}>0.05)$.

\section{Causal item and disease outcomes}

Finally, we analyzed how the categories of the main reported cause (omitting second and third causes) were associated with disease outcomes six months after cardiac rehabilitation. The patients reported whether they experienced the disease deterioration or underwent hospitalization during the period of the last six months (Table 4).

Table 4. Disease outcomes after 6 months depending on perception of main cause of illness $(n=175)$.

\begin{tabular}{lcccc} 
Main cause & \multicolumn{2}{c}{$\begin{array}{c}\text { Cardiac illness } \\
\text { deterioration }\end{array}$} & \multicolumn{2}{c}{ Hospitalivation } \\
& $\%$ & P & $\%$ & P \\
Lifestyle & 21.8 & 0.099 & 7.3 & 0.039 \\
Psychological causes & 38.6 & 0.164 & 20.5 & 0.347 \\
\hline Natural causes & 34.5 & 0.590 & 20.7 & 0.419 \\
Working conditions & 35.3 & 0.636 & 29.4 & 0.156 \\
\hline Body changes & 25.0 & 0.779 & 18.8 & 0.724 \\
Environmental factors & 0.0 & - & 0.0 & - \\
\hline Other causes & 20.0 & 1.000 & 20.0 & 0.583 \\
Unspecified & 33.3 & 1.000 & 33.3 & 0.156 \\
\hline Total & 30.3 & & 17.7 & \\
\hline
\end{tabular}

\begin{tabular}{|c|c|}
\hline Lifestyle & $\begin{array}{l}\text { Food/nutrition (e. g. salt, fatty food, coffee, sugar, unbalanced diet), addictive } \\
\text { behaviours (smoking, drinking alcohol, illicit drug use), inadequate physical activity } \\
\text { (too high or too low), poor treatment adherence (ignorance of treatment regimen, } \\
\text { improper drug use, rare health check-ups), fast pace of life, fatigue and lack of rest }\end{array}$ \\
\hline $\begin{array}{l}\text { Psychological } \\
\text { causes }\end{array}$ & $\begin{array}{l}\text { Stress, nervousness, tension (at home, at work, in life overall), conflicts with relatives, } \\
\text { worrying about relatives, nursing of family members, bereavement, type A personality, } \\
\text { emotional sensitivity, worrying, workaholism, depressiveness, loneliness }\end{array}$ \\
\hline $\begin{array}{l}\text { Natural } \\
\text { causes }\end{array}$ & Heredity, genetics (genes), age \\
\hline $\begin{array}{l}\text { Working } \\
\text { conditions }\end{array}$ & $\begin{array}{l}\text { Manual labour, hard work, high workload, intense work, harmful or toxic conditions at } \\
\text { work (chemical substances, noise), shift work, night work }\end{array}$ \\
\hline $\begin{array}{l}\text { Body } \\
\text { changes }\end{array}$ & $\begin{array}{l}\text { High blood pressure, atherosclerosis, high cholesterol, overweight and obesity, diabetes } \\
\text { mellitus, influenza and pneumonia complications, cardiovascular disease, disorders of } \\
\text { cardiac activity, chest pain, other defined or undefined diseases and comorbidities }\end{array}$ \\
\hline $\begin{array}{l}\text { Environmental } \\
\text { factors }\end{array}$ & Radiation and environment \\
\hline $\begin{array}{l}\text { Other } \\
\text { causes }\end{array}$ & $\begin{array}{l}\text { Economic situation in country, lack of financial resources, low salary, inappropriate } \\
\text { treatment, the life overall }\end{array}$ \\
\hline
\end{tabular}

Figure 1. Categories of perceived illness causes: empirical responses 
The study revealed that after six months nearly one-third of respondents (30\%) suffered cardiac illness deterioration and $18 \%$ were hospitalized. The lower occurrence of untoward health events was more common among patients who had a predominant perception that their disease was determined by lifestyle causes - they had a trend to less likely experience health deterioration $(\mathrm{p}=0.099)$ and they had a significantly lower risk of hospitalization $(p=0.039)$. All other causal categories were not related with abovementioned outcomes, though it can be noted that psychological causes were related with slightly higher risk of health deterioration, while working conditions - with hospitalization $(\mathrm{p}>0.05)$.

\section{Discussion}

Even though the illness perception has been investigated for several decades, the causal item is still analyzed qualitatively and has no clearly defined causal categories, which restricts the comparison of the findings across studies. Thus, our study aimed to try clearly defining the main causal categories as perceived by patients with a potential that it may be used in future research. Though our study approached only the patients with acute coronary syndrome, we expect that it could be tested for other clinical samples as well.

In this study, we defined seven causal categories in illness perception: lifestyle, psychological causes, natural causes, working conditions, body changes, environmental factors, and other causes. It can be noted that authors of IPQ scale (Weinman et al., 1996) were the first ones to define causal categories in illness perception research - they proposed eight causal categories: 'germ or virus', 'diet', 'pollution', 'genetics', 'chance', 'stress', 'my own behavior', and 'other people behavior'. However, later research on causal perceptions was relatively scarce, being mainly limited to qualitative analysis and almost never following eight causal categories. The developers of IPQ-R (Moss-Morris et al., 2002) suggested a more detailed list for a responder to choose - they proposed 18 illness causes that mainly follow that by Weinman et al. (1996) but also specifying them. For example, behavioral factors were specified to 'alcohol', 'smoking', the psychosocial causes were also introduced (such as 'negative mental attitude' or 'family worries') as well as 'poor medical care' or 'overwork'. However, later research was also not in favor of the causal item, because a meta-analysis by Broadbent et al. (2015) concluded that 'more studies should include and analyze the causal item'. They noted that the most frequently mentioned causes were 'psychological stress', 'genetics', and 'illness behaviors' (Broadbent et al., 2015). Meanwhile Duwe et al. (2014) grouped the causal beliefs to six categories: 'psychosocial', 'behavioral', 'natural', 'physical', 'supernatural', and 'other'. Other studies did not use any consistent categorization. Due to the lack of research on the causal item of illness perception, there are not many studies to compare with ours. In our study, patients with acute coronary syndrome mainly emphasized lifestyle and psychological factors. However, the study analyzing older adults with hypertension found that they perceive the physical, natural and partly - psychosocial causes as the most important (Duwe et al., 2014), while patients after acute myocardial infarction mainly emphasized stress and high cholesterol (Weinman et al., 2000). Other samples are more likely to believe that the cause of their illness was a chance (Weinman et al., 1996), smoking (Hoogerwerf et al., 2012), over-exertion (Sluiter \& Frings-Dresen, 2008) and alike.

The most common causal category in our study was labeled as 'lifestyle'. Majority of previous authors tended to label this catego- ry as 'behavioral factors', however, we suggest the term 'lifestyle', because the term 'behavioral' is too broad and may include not only lifestyle-related behaviors but also other behaviors such as a shift work, high workload or workaholism that we assigned to categories of 'working conditions' or 'psychological factors'. Nevertheless, we admit that the term 'behavioral factors' may still be used in the future.

We defined the next most important causal category as 'psychological factors'. We suggest using the term 'psychological' rather than 'psychosocial' causes, because 'social' may imply the factors that are less closely dependent upon the person. This is especially relevant when considering economic factors that are part of a social environment. It can also be noted that in our analysis and categorization process there were quite extensive discussions about the subcategory of responses which was initially labeled as 'psychological factors at work'. This subcategory could be assigned either to 'psychological factors' or to 'working conditions'. We decided to add them to the former category - this was based on additional data analysis (not presented in Results) which revealed that illness perception among patients with 'psychological factors at work' was more similar to that of patients emphasizing 'psychological factors' rather than 'working conditions'.

The category of 'natural causes' implying hereditary factors and aging is consistent with previous literature and most likely does not need specific explanations. In contrast to this, in our study relatively rare causal category emerged - the 'working conditions'. In previous research it was mentioned in some categories (such as job stress or overwork); however, it had emphasis neither on theoretical nor empirical perspective. In our study, this was a category that was much more common than previously defined 'environmental factors', such as air pollution that were mentioned very rarely in our study. This may be a result of the study sample patients with acute coronary syndrome hardly tend to attribute their condition to environmental factors. However, in cases of other diseases, especially respiratory disorders or allergies this category may be of higher importance in patients' illness perceptions.

In our study, the category of 'body changes' emerged from several definitions in previous research. We defined it as body changes that mainly occur due to physiological or anatomical responses to environment, lifestyle or illnesses. Previously this type of causes was referred to as 'physical' (Duwe et al., 2014) as well as narrower subcategories 'accident or injury' or 'altered immunity' (MossMorris et al., 2002). From our perspective, it is relevant to distinguish between 'natural causes' and 'body changes' - they may overlap, but the former ones are unavoidable, while the latter ones have a certain level of personal responsibility. Likewise, we prefer to distinguish 'body changes' from 'lifestyle', because the perception of lifestyle as a cause of illness is more abstract but in the same time more likely to be changed, while the illness causes that are considered as body changes could be harder to change, especially outside health care system. In short, the lifestyle implies the patient's emphasis on the exposure, while the body changes - on the outcome (or a mediator to the outcome).

The last suggested category is 'other causes' which includes different causal beliefs that do not fall into the abovementioned categories. This is in line with Duwe et al. (2014) suggested category, though they assigned here the missing responses as well. However, we propose that missing responses would stay as missing or unknown causes, because some people may report no causal perceptions due to lack of time, superficial approach to survey or just be reluctant to write words rather than tick responses. Also, some responders may perceive certain causes of illness from the abovementioned categories without mentioning them, so assigning 
the missing responses to 'other causes' could lead to misclassification bias. It is worth to mention that participants who reported other causes had the most threatening perception of their illness. This may be due to lack of knowledge of acute coronary syndrome, so these patients indicated very common or accidental causes of their illness.

In our study, the psychological causes was the most important causal category associated with health-related outcomes. This could be explained by the fact that the responses assigned to this category (e.g. stress, nervousness, tension, personality, emotional sensitivity) in many cases have non-specific but predominantly negative health effects. This has been proved in previous studies (Jokela et al., 2014; Garfin et al., 2018; Kupper \& Denollet, 2018).

On the other hand, the perception of acute coronary syndrome as caused by lifestyle factors was related to lower rates of hospitalization and health deterioration. These findings suggest that participants who believed that acute cardiac syndrome was caused by their unhealthy lifestyle, may have changed their lifestyle after the cardiac event to a healthier one, in order to avoid the recurrence of the disease. This supports the idea that personal responsibility for own's health as determined by lifestyle leads to better health outcomes: for instance, Weinman et al. (2000) found that patients who attribute own myocardial infarction to lifestyle are more likely to have positive changes in health behaviors compared to patients who attribute it to stress or hereditary factors. Therefore it could be useful to increase and support the patients' awareness that lifestyle not only may lead to negative health outcomes but also prevent recurrent events. Such interventions as education and empowerment may be effective for patients starting from early rehabilitation after acute cardiac event. In our study, we analyzed the causal item from two quantitative perspectives - taking into account only the first (main) cause or all three mentioned causes. Very high correlation between those two different approaches suggests that in analyses of overall data (not of a particular patient) it may be sufficient to analyze only the main cause that is reported. This would simplify the calculations and interpretation of findings in contrast to the more sophisticated approach of rating the causes. Of note, the correlational analysis of causal rankings revealed that the defined seven categories correlate poorly at levels of $\rho<0.25$ which indirectly indicates the independence of causes, suggesting that the categories overlap only slightly. It should be kept in mind that the categories of illness causes defined in our study were based on patients with acute coronary syndrome. It is likely that for some other diseases these categories may not represent the spectrum of main causes, though we expect that for the majority of diseases this categorization still could be applicable. Since we tried to define the generic causal categories, we see the potential to use this categorization under different conditions and patients in further research.

\section{Conclusions}

To conclude, we suggest that the proposed categorization of BIPQ causal item could be tested in the future research among different samples. The analysis of BIPQ causal item may take into account only the main cause, while the second and third causes could be relevant for more detailed analysis. The perception that acute coronary syndrome is mainly due to lifestyle factors is associated with better health-related outcomes compared to other causal perceptions.

\section{References}

Broadbent, E., Petrie, K., Main, J., \& Weinman, J. (2006). The Brief Illness Perception Questionnaire. Journal of Psychosomatic Research, 60, 631-637.

Broadbent, E., Wilkes, C., Koschwanez, H., Weinman, J., Norton, S., \& Petrie, K. J. (2015). A systematic review and meta-analysis of the Brief Illness Perception Questionnaire. Psychology \& Health, 30(11), 1361-1385.

Brooks, J., McCluskey, S., Turley, E., King, N. (2015). The Utility of Template Analysis in Qualitative Psychology Research. Qualitative Research in Psychology, 12, 202-222.

Duwe, E. A. G., Koerner, K. M., Madison, A. M., Falk, N. A., Insel, K. C., \& Morrow, D. G. (2014). Defining older adults' perceived causes of hypertension in the Brief Illness Perception Questionnaire. Health Education Journal, 73(6), 731-745.

Fleiss, J. L. (1981). Statistical methods for rates and proportions (2nd ed.). New York: John Wiley. ISBN 0-471-26370-2.

Garfin, D. R., Thompson, R. R., Holman, E. A. (2018). Acute stress and subsequent health outcomes: A systematic review. Journal of Psychosomatic Research, 112, 107-113.

Hoogerwerf, M. A., Ninaber, M. K., Willems, L. N. A., \& Kaptein, A. A. (2012). "Feelings are facts": Illness perceptions in patients with lung cancer. Respiratory Medicine, 106, 1170-1176.

Jokela, M., Pulkki-Råback, L., Elovainio, M., Kivimäki, M. (2014). Personality traits as risk factors for stroke and coronary heart disease mortality: pooled analysis of three cohort studies. Journal of Behavioral Medicine, 37, 881-889.

Kupper, N., Denollet, J. (2018). Type D Personality as a Risk Factor in Coronary Heart Disease: a Review of Current Evidence. Current Cardiology Reports, 20, 104.

Lambregts, A.J.P. (2017). The Relationship between Illness Perception and Health-Related Quality of Life among Colorectal Cancer Patients: The role of Socioeconomic Status. B.Sc. thesis, Tilburg University, the Netherlands.

Landis, J.R, \& Koch, G. G. (1977). The measurement of observer agreement for categorical data. Biometrics, 33, 159-174.

Lau, R.R., \& Hartman, K. A. (1983). Common sense representations of common illnesses. Health Psychology, 2(2), 167185.

Leventhal, H., Meyer, D., \& Nerenz, D. (1980). The common sense model of illness danger. Medical Psychology, 2, 7-30.

Leventhal, H., \& Nerenz, D. (1985). The assessment of illness cognition. In P. Karoly (Ed) Measurement Strategies in Health Psychology, 517-555. New York: Wiley.

Leventhal, H., Benyamini, Y., Brownlee, S., Diefenbach, M., Leventhal, E. A., Patrick-Miller, L., \& Robitaille, C. (1997). Illness representations: Theoretical foundations. In K. Petrie \& J. Weinman (Eds.), Perceptions of health and illness (pp. 1-19). Amsterdam: Harwood Academic.

Marke, V., \& Bennett, P. (2017). Predicting negative emotional states following first onset acute coronary sindrome. Journal of Health Psychology, 22(6), 765-775.

Moss-Morris, R., Weinman, J., Petrie, K. J., Horne, R., Cameron, L. D., \& Buick, D. (2002). The Revised Illness Perception Questionnaire (IPQ-R). Psychology \& Health, 17, 1-16.

Petrie, K. J., \& Weinman, J. (2006). Why illness perceptions matter. Clinical Medicine, 6, 536-539.

Sluiter, J. K., \& Frings-Dresen, M. H. W. (2008). Quality of life and illness perception in working and sick-listed chronic RSI 
patients. International Archives of Occupational and Environmental Health, 81, 495-501.

Weinman, J., Petrie, K. J., Moss-Morris, R., \& Horne, R. (1996).

The illness perception questionnaire: A new method for assessing the cognitive representation of illness. Psychology
\& Health, 11, 431-445.

Weinman, J., Petrie, K. J., Sharpe, N., \& Walker, S. (2000). Causal attributions in patients and spouses following firsttime myocardial infarction and subsequent lifestyle changes. British Journal of Health Psychology, 5, 263-273. 